João G. de Souza Junior, Guanis de B. Vilela Júnior e Mudanças Ocorridas na Cidade de Uberaba-MG... Rute E. Tolocka

\title{
MUDANÇAS OCORRIDAS NA CIDADE DE UBERABA-MG E SUAS POSSÍVEIS INFLUÊNCIAS NO LAZER INFANTIL
}

Recebido em: 24/10/2009

Aceito em: 31/05/2010

\author{
João Gurgel de Sousa Junior \\ Guanis de Barros Vilela Júnior \\ Rute Estanislava Tolocka
}

Universidade Metodista de Piracicaba

Piracicaba - São Paulo - Brasil

RESUMO: Mudanças no cotidiano reduziram oportunidades para o lazer infantil, sendo necessário verificá-las para levantar subsídios para políticas públicas. Este estudo refere-se à mudanças ocorridas em uma cidade em Minas Gerais, que podem estar ligadas à atividades infantis. Documentos fornecidos por instituições públicas foram analisados bem como respostas de pais de 20 crianças de uma escola privada, escolhidas aleatoriamente. Verificou-se que a população da cidade, bem como o número de carros e crimes aumentou, enquanto que o número de lugares públicos para o lazer permaneceu quase o mesmo. A maior parte do tempo estas crianças brincam dentro das suas próprias casas com atividades de baixo gasto enérgico; elas não têm muitos amigos para brincar. Mudanças na política pública social precisam ser realizadas para que o sistema de urbanização traga mais segurança aos moradores e garanta os direitos de criança ao lazer.

PALAVRAS-CHAVE: Atividades de Lazer. Exercício. Desenvolvimento Infantil.

\section{CHANGES AT UBERABA CITY (MG) AND THEIR POSSIBLE INFLUENCES IN CHILDHOOD LEISURE}

ABSTRACT: Changes in daily life have reduced child opportunities for leisure and it is necessary to know what has been changed in order to bring subsidies for public policies. This study is concerning with changes in one city from Minas Gerais State - Br that may be linked with child activities. Documents provided by public institutions were analyzed as well the answers from 20 parents of children who studied in a private school and were randomized chose. It was found that city population, as well the number of cars and crimes had increased while the numbers of public places for leisure remain nearly the same. Most of the time those children has played inside of their own houses, doing activities with few energetic cost; they don't have many friends to play with. Social public policies need to be developed bringing projects where urbanization system may give more security for the people guaranteeing child's rights for leisure. 
João G. de Souza Junior, Guanis de B. Vilela Júnior e Mudanças Ocorridas na Cidade de Uberaba-MG... Rute E. Tolocka

\section{KEYWORDS: Leisure Activities. Exercise. Child Development.}

\section{Introdução}

As transformações socioeconômicas, culturais e tecnológicas ocorridas nas últimas décadas modificaram o estilo de vida das pessoas, alterando significativamente o seu cotidiano o que, entre outras conseqüências, interfere negativamente na experiência prática do lazer (SILVA E NUNES, 2008). Essas alterações atingem também as crianças, que alteraram seu estilo de vida, principalmente no que tange ao lazer na forma de brincadeiras, esporte, jogos e outras manifestações e aos espaços públicos disponíveis para isto.

Contudo, sabe-se da importância do lazer para a criança. Várias legislações garantem esse direito, tais como: a Declaração dos Direitos da Criança, aprovada pelas Nações Unidas, em 20 de novembro de 1959, para que se a infância seja feliz, no seu princípio $7^{\circ}$ declara que: “A criança deve desfrutar plenamente de jogos e brincadeiras, os quais deverão estar dirigidos para a educação; a sociedade e as autoridades públicas se esforçarão para promover o exercício desse direito," e ainda a lei n. 8.069, de 13 de julho de 1990 do Estatuto da Criança e Adolescente dispõe que a criança tem o direito de brincar, praticar esportes e divertir-se. (BRASIL, 1990).

Prodócimo e Navarro (2008) enfocam que as crianças precisam brincar, pois é inseridas nesse contexto que elas se aproximam e descobrem as pessoas e o mundo, facilitando a comunicação e a interação com o próximo, promovendo o seu desenvolvimento. O movimento, a brincadeira livre, a criação de soluções na dificuldade do ambiente são de interesse e necessidade da criança.

De acordo com Silva et al (2006) é de suma importância a vivência do lúdico, na forma do jogo, de brincadeira, de esporte e ou de corridas, para que as crianças 
João G. de Souza Junior, Guanis de B. Vilela Júnior e Mudanças Ocorridas na Cidade de Uberaba-MG... Rute E. Tolocka

experimentem várias formas de movimento e despertem a criatividade. As mudanças ocorridas no estilo de vida das crianças nos últimos anos podem modificar as possibilidades para concretização dessas atividades (RODRIGUES et al, 2007 CARLOS NETO, 2005, ESCOBAR E VALENTE, 2007, ABREU et al 2008).

Segundo Oliveira (2004), Silva e Nunes (2008) e Prodócimo e Navarro (2008) a criança perdeu seu espaço nos centros urbanos, após um crescimento acelerado e imediatista das cidades, provocando valorização dos terrenos, aumento da insegurança e do tráfego de veículos, fazendo com que as crianças tenham cada vez menos locais para o lazer. A mercantilização do espaço urbano trouxe conseqüências para o mundo da criança, pois aquilo que lhe era extremamente importante, gradativamente está sendo tirado: o quintal, a rua, o jardim, a praça, a várzea, e o espaço livre (PERROTTI, 1982).

Conseqüentemente as brincadeiras foram levadas para dentro da casa, limitando suas possibilidades, prevalecendo restrições ao movimento e às possibilidade de novas descobertas (OLIVEIRA, 2004, NEVES et al,2004). Pouco tempo tem sido dispensado para as brincadeiras, até mesmo com crianças mais novas (2 a 06 anos), resultando na restrição de possibilidades da criação, do imaginário, de experimentar novas vivências e conhecer melhor os outros e o mundo (SILVA; TOLOCKA, 2006; FARIA et al (2007) e TOLOCKA et al (2008).

A falta de espaços adequados restringe as oportunidades do lazer, pois os espaços que estão sendo oferecidos às crianças na escola e fora dela não estão sendo suficientes para suas necessidades de movimento, do lúdico, do jogo. $\mathrm{O}$ aumento populacional e a expansão dos espaços físicos devem ser levados em conta para a construção de políticas públicas para o lazer. (BRITO, 2006). 
João G. de Souza Junior, Guanis de B. Vilela Júnior e Mudanças Ocorridas na Cidade de Uberaba-MG... Rute E. Tolocka

Para Neves et al (2004) as autoridades governamentais deveriam recorrer à informações sobre o cotidiano infantil e a necessidade de espaços públicos adequados para a vivência da infância, para que implantar políticas públicas voltadas para o lazer. Há necessidade de construção de novos locais, adequados, seguros, com equipamentos específicos e com desenvolvimento de atividades de lazer, sem desconsiderar os espaços já existentes e significativos para as crianças. Kassouf (2007); Campos e Debortoli (2007) observaram que há necessidade de novos olhares, com políticas sociais que permitam as crianças o desfrute do lazer.

No entanto, poucos estudos relacionam mudanças ambientais com as atividades realizadas pelas crianças. Assim o objetivo deste estudo é analisar o impacto de mudanças ocorridas na cidade nas atividades realizadas no cotidiano infantil, para levantar subsídios que possam auxiliar na elaboração de políticas públicas sobre o lazer infantil.

\section{Metodologia}

O estudo foi realizado na cidade de Uberaba-MG. Para verificação das alterações ocorridas nesta cidade nos últimos dez anos foram coletados dados através de correspondência eletrônica com: IBGE (dados populacionais), Fundação João Pinheiro, Instituição pública estadual vinculada à secretaria de Estado de Planejamento e Gestão de Minas Gerais, voltada para a realização de projetos de pesquisa aplicada, consultorias (dados sobre violência urbana), DETRAN/MG, Departamento de trânsito (Frota de veículos), 25 a Superintendência Regional de Ensino de Minas Gerais (escolas estaduais e alunos matriculados em período integral), Seção de Inspeção Escolar, do 
João G. de Souza Junior, Guanis de B. Vilela Júnior e Mudanças Ocorridas na Cidade de Uberaba-MG... Rute E. Tolocka

Departamento de Apoio Pedagógico da Secretaria Municipal de Educação de Uberaba MG (escolas e alunos da rede municipal).

Informações sobre o Sistema Urbano, Locais para a prática esportiva de lazer e usuários foram retiradas da revista, "Uberaba em dados" organizada pela Prefeitura Municipal de Uberaba, e disponibilizada pela mesma. Os dados do ano de 1998 foram coletados na edição do ano de 1999, tendo como base o ano de 1998 e os de 2006, na edição de 2008, base 2007.

O cotidiano infantil foi investigado através de uma versão adaptada do Formulário de Atividade do Cotidiano Infantil Silva (2006). O formulário permite o registro em horas e minutos do tempo gasto em atividades fisicamente ativas, tais como esportes, dança lutas e atividades fisicamente passivas (assistir TV, jogos eletrônicos e de computador, sono, estudo e transporte). A coleta foi realizada durante a semana; sendo coletados dados referentes a atividades realizadas no domingo anterior e no dia anterior à pesquisa. Sendo assim, os dados foram referentes a algum dia útil da semana e ao domingo. Os formulários foram respondidos por vinte pais ou responsáveis, nas dependências de uma escola privada, escolhidos aleatoriamente.

Os dados acerca das atividades do cotidiano das crianças foram organizados em uma planilha do programa Microsoft Excel e foi calculado o tempo total (em horas) destinado ao sono e às atividades fisicamente ativas e passivas. Dessa forma, foram submetidos aos testes de Shapiro-Wilk e Levene para verificação, respectivamente, da distribuição normal dos dados e homogeneidade das variâncias. Como os dados apresentaram distribuição não normal, foi utilizado o teste de Wilcoxon para comparações entre atividades fisicamente ativas e passivas e entre os períodos da semana (duas amostras dependentes). 
João G. de Souza Junior, Guanis de B. Vilela Júnior e Mudanças Ocorridas na Cidade de Uberaba-MG... Rute E. Tolocka

As análises estatísticas foram realizadas utilizando-se o programa Statistica 8.0 (StatSoft, Inc. 2007) e as diferenças observadas foram consideradas significativas quando o nível de significância (p) foi menor que 0,05 .

\section{Resultados e Discussão}

A cidade de Uberaba- MG apresenta várias das mudanças ambientais relatadas em outros municípios em regiões urbana. Houve aumento no número de habitantes, em 1998 eram 243.948 moradores e em 2008, 292.377 (dados estimativos, por não ter havido contagem nesses anos citados). No ano de 1998, Uberaba possuía um total de 2.135 ruas e no ano de 2006, 2.757; no tocante as Praças, a cidade dispunha de 154 no ano de 1998 e em 2006, 190; em 1998 a cidade registrava 185 avenidas e em 2006, 242. Em relação aos parques municipais não houve alteração a cidade disponibilizava no ano de 1998 dois parques que são os mesmos encontrados em 2009.

Em relação a ginásios poliesportivos, quadras abertas, quadras cobertas e de areia, a cidade disponibilizava no ano 1998 de 106 e em 2007 de 118. Em relação aos campos de Futebol amador, comunidade e profissional a cidade disponibilizava no ano de 1998 de 34 e em 2007 de 41. Em relação aos parques municipais, a cidade disponibilizava no ano de 1998 de dois, sendo os mesmos em 2009.

O total de veículos existentes em Uberaba no ano de 1999 era de 79.145 e em 2009 de 139.273. A frota de 2009 foi atualizada em 04/08/2009.

Em relação aos diferentes tipos de crimes violentos, obedecendo a caracterização determinada pelo Código Penal Brasileiro foram encontradas em 1998, 1106 ocorrências classificadas como homicídio, homicídio tentado, estupro, roubo, roubo a mão armada, e em 2008, 2043; ocorrências de crimes violentos contra o patrimônio 
João G. de Souza Junior, Guanis de B. Vilela Júnior e Mudanças Ocorridas na Cidade de Uberaba-MG... Rute E. Tolocka

(roubo e roubo a mão armada) foram registradas no ano de 1998 - 924 e em 2008, 1932; os crimes violentos contra a pessoa (homicídio, homicídio tentado e estupro) diminuíram um pouco, sendo observadas 182 ocorrências em 1998 e 111 em 2008; porém o número de Homicídios, aumento de 24 ocorrências em 1998 para 29 em 2008.

Diante desses dados fica clara a expansão do sistema urbano, já relatada por Brito (2006), como fenômeno recente em relação à expansão física das cidades, houve aumento dos logradouros públicos, inclusive de locais para a prática esportiva, mas também ocorreu aumento da violência e do tráfico. É importante ressaltar que o aumento dos logradouros públicos, não significa aumento ao acesso para a prática de atividades motoras e ao lazer, pois segundo, Prodócimo e Navarro (2008), Silva e Nunes (2008), a violência que gera insegurança, pode impedir o aproveitamento desses espaços e impor às crianças restrições ao uso desses locais públicos, o que pode diminuir a possibilidade do desfrute dos prazeres das brincadeira, jogos, entre outros.

Em relação ao total de alunos matriculados em escolas em tempo integral na rede estadual e municipal, no ano de 1999 verificava-se 467 alunos e em 2009, 3.999. O número de alunos matriculados em escola de tempo integral confirma a posição de Cavaliere (2007), que enfatiza o crescimento destas a partir da virada do século. Porém é importante ressaltar que essas escolas de acordo com Tolocka et al (2008), absorvem as crianças cada vez mais cedo, onde poucas atividades motoras ativas de brincar, jogar, entre outras, são desenvolvidas, priorizando as atividades passivas, em prejuízo das crianças, no que tange a desenvolvimento motor, ao crescimento físico e a possibilidade de criatividade.

De acordo com o preenchimento do formulário de atividades do cotidiano infantil, sobre quantas vezes as crianças costumam freqüentar esses locais por semana, 
João G. de Souza Junior, Guanis de B. Vilela Júnior e Mudanças Ocorridas na Cidade de Uberaba-MG... Rute E. Tolocka

encontraram-se os seguintes dados: As praças e parques são freqüentados por uma criança por três vezes; por três crianças por duas vezes; por seis crianças uma vez; e dez crianças não freqüentam. A igreja é freqüentada por uma criança por três vezes; por dez crianças uma vez; e nove crianças não freqüentam. O restaurante é freqüentado por uma criança por cinco vezes; por uma criança por três vezes; por duas crianças por duas vezes; nove crianças por uma vez; e sete crianças não freqüentam. O shopping é freqüentado por duas crianças por três vezes; quatro crianças por duas vezes; nove crianças por uma vez; e cinco crianças não freqüentam. A Lan house é freqüentada por uma criança por uma vez; e dezenove crianças não freqüentam. O clube é freqüentado por três crianças por três vezes; por quatro crianças duas vezes; por cinco crianças uma vez; e oito crianças não freqüentam.

TABELA 1

Distribuição da freqüência absoluta das crianças aos locais freqüentados.

\begin{tabular}{lrccccc}
\hline Local & \multicolumn{7}{c}{ Freqüência Semanal } \\
\hline Parques/praças & 0 & 1 & 2 & 3 & 4 & 5 \\
Igreja & 10 & 6 & 3 & 1 & 0 & 0 \\
Restaurante & 9 & 10 & 0 & 1 & 0 & 0 \\
Shopping & 7 & 9 & 2 & 1 & 0 & 1 \\
Lan house & 5 & 9 & 4 & 2 & 0 & 0 \\
Clube & 19 & 1 & 0 & 0 & 0 & 0 \\
& 8 & 5 & 4 & 3 & 0 & 0 \\
\hline
\end{tabular}

Em relação aos locais em que as crianças freqüentam e podem brincar com a sugestão de resposta para os pais ou responsáveis de nunca, às vezes e sempre, encontrou-se as seguintes indicações: A garagem da casa é apontada como nunca por oito pais; às vezes por nove e sempre por três. A rua de casa foi indicada por quinze pais como nunca, às vezes por quatro; e sempre por uma. As ruas do bairro foram indicadas por dezoito pais como nunca; dois às vezes; e nenhuma apontou como sempre. O quintal de casa foi indicado por seis pais como nunca; seis às vezes; e oito sempre. 
João G. de Souza Junior, Guanis de B. Vilela Júnior e Mudanças Ocorridas na Cidade de Uberaba-MG... Rute E. Tolocka

Campo ou terreno baldio foi apontado por dezoito pais como nunca; um às vezes; e um sempre. A casa do vizinho foi indicada por quinze pais como nunca; cinco às vezes; e nenhum apontou sempre. O salão do prédio foi indicado por quinze pais como nunca; quatro como às vezes; e um como sempre. Os cômodos da casa foram apontados por nenhum pai como nunca; três como às vezes; e dezessete como sempre.O clube foi indicado por seis pais como nunca; dez como às vezes; e quatro como sempre.O parque foi apontado por nove pais como nunca; dez como às vezes; e um como sempre.A praça foi apontada por sete pais como nunca; doze como às vezes; e um como sempre. Outros locais foram indicados por dois pais como sempre, e um às vezes, referindo-se a chácara, conforme pode ser observado na (TAB. 2).

\section{TABELA 2}

Distribuição das crianças em relação aos locais permitidos pelos pais para brincar e a frequiência dos mesmos

\begin{tabular}{lccc}
\hline \multicolumn{1}{c}{ Locais } & \multicolumn{3}{c}{ Frequência } \\
\hline & Nunca & Às vezes & Sempre \\
Garagem da casa & 8 & 9 & 3 \\
Rua de casa & 15 & 4 & 1 \\
Ruas do bairro & 18 & 2 & 0 \\
Quintal da casa & 6 & 6 & 8 \\
Campo ou terreno & 18 & 1 & 1 \\
Casa do vizinho & 15 & 5 & 0 \\
Salão do prédio & 15 & 4 & 1 \\
Cômodos da casa & 0 & 3 & 17 \\
Clube & 6 & 10 & 1 \\
Parque & 9 & 10 & 1 \\
Praça & 7 & 12 & \\
Outro local & 1 & 2 & \\
\hline
\end{tabular}

Verifica-se assim que a freqüência das crianças nas praças e parques foi pequena enquanto houve grande ocupação do cômodo e do quintal da casa como espaço para brincar da criança e pouca utilização da rua. Isto pode ter ocorrido porque a violência na 
João G. de Souza Junior, Guanis de B. Vilela Júnior e Mudanças Ocorridas na Cidade de Uberaba-MG... Rute E. Tolocka

cidade aumentou, bem como o trafego urbano, nos últimos anos, e isto pode estar gerando insegurança e impedindo o aproveitamento destes espaços públicos, como previsto por Prodócimo e Navarro (2008), Silva e Nunes (2008). Este fato é preocupante também porque as crianças acabam acostumando a brincar sozinhas, o que pode dificultar sua interação social.

O principal meio de transporte utilizado pelas crianças da residência até a escola é o carro, que foi indicado por todos os responsáveis das dezenove crianças, com média de tempo gasto de 11,6 min, sendo que o menor tempo citado foi de 5 min e o maior tempo gasto de $20 \mathrm{~min}$. Isto pode ter ocorrido porque os dados foram coletados em uma escola da rede privada de ensino, freqüentada predominantemente por pessoas de poder aquisitivo mais alto que tem no automóvel um veiculo mais rápido e seguro de transporte, o que de outro lado, dificulta ainda mais a integração social das crianças, que passam a ir e vir muitas vezes apenas com a companhia dos pais, perdendo a oportunidade de brincar pelo caminho, que ocorria em outras décadas.

As crianças permanecem em média quatro $4 \mathrm{~h} 38 \mathrm{~min}$ na escola. Se for observado o tempo de ida a escola (11,6 min) e volta (11,6 min), mais a permanência na escola, a criança destina $5 \mathrm{~h} 23$ min com ocupações escolares.

Foi constatado que as crianças durante a semana dormem em média 552 minutos (9h12min), sendo que o maior período encontrado foi de $11 \mathrm{~h} 00 \mathrm{~min}$ horas e o menor de 06h50min.

Em relação às atividades fisicamente ativas realizadas durante a semana, no período fora da escola, foi encontrado que sete crianças ajudaram a arrumar e a organizar a casa; oito crianças que participaram de atividades sobre rodas (bike, patins, skate, rolemã, outras); a participação em jogos ou brincadeira de chute, lançamento ou 
João G. de Souza Junior, Guanis de B. Vilela Júnior e Mudanças Ocorridas na Cidade de Uberaba-MG... Rute E. Tolocka

recepção de objetos com o pé, envolveu cinco crianças; em relação às atividades envolvendo jogos ou brincadeiras de lançamento ou recepção com as mãos, encontrouse a participação de seis crianças, sendo o tênis, o vôlei, disco e bola os esportes ou brincadeiras citadas; nos jogos ou brincadeiras que envolvem correr, saltar, trepar, ou outros deslocamentos, foi observado a participação de cinco crianças, sendo o piquepega e corridas atividades citadas; a participação em escolinhas de esportes com orientação de um professor/treinador contou com a participação de 6 crianças; nenhuma criança praticou qualquer tipo de luta; em relação as crianças que participaram de algum tipo de dança, encontrou se três;foi encontrado dois crianças que fez algum tipo de passeio a pé. O tempo médio e mediano gasto em todas as atividades pode ser vista na (TAB. 3).

\section{TABELA 3}

Tempo médio e mediano (em minutos) gasto em cada atividade fisicamente ativa, durante a semana, fora da escola

\begin{tabular}{lll}
\hline \multicolumn{1}{c}{ Atividade } & \multicolumn{2}{c}{ Semana } \\
\cline { 2 - 3 } & \multicolumn{1}{c}{ Média } & \multicolumn{1}{c}{ Mediana } \\
\cline { 2 - 3 } & (+_desvio padrão) & (Mín.-Máx.) \\
\hline Arrumar casa & $13,0(+-34,1)$ & $0,0(0,0-150,0)$ \\
Cuidar de crianças & - & - \\
Sobre Rodas & $16,0\left(+\_26,8\right)$ & $0,0(0,0-90,0)$ \\
Atividades com os pés & $16,3\left(+\_31,7\right)$ & $0,0(0,0-120,0)$ \\
Atividades com as mãos & $27,0(++44,5)$ & $0,0(0,0-120,0)$ \\
Atividades deslocamentos & $12,0\left(+\_22,8\right)$ & $0,0(0,0-60,0)$ \\
Escola de esportes & $22,8\left(+\_34,8\right)$ & $0,0(0,0-120,0)$ \\
Luta & - & - \\
Dança & $12,0\left(+\_32,9\right)$ & $0,0(0,0-120,0)$ \\
Passeio a pé & $2,5\left(+\_7,9\right)$ & $0,0(0,0-30,0)$ \\
\hline
\end{tabular}

Em relação às atividades fisicamente passivas, durante a semana, encontrouse 10 crianças que leram (livro, revista, jornal...); todas (20) as crianças assistiram TV, 10 crianças ouviram música; 13 conversaram com colegas/amigos; foi constatado que 
João G. de Souza Junior, Guanis de B. Vilela Júnior e Mudanças Ocorridas na Cidade de Uberaba-MG... Rute E. Tolocka

12 crianças usaram o computador / Internet durante o dia; três jogaram vídeo game; 10 crianças utilizaram brinquedos industrializados; 14 crianças estudaram / ou fizeram deveres escolares; encontrou-se cinco crianças que tiveram como atividade durante o dia: modelar, montar, desenhar, recortar ou fazer colagem; somente duas crianças dormiram durante o dia; duas crianças participaram de atividade de escola de música; curso de línguas ou computação teve apenas a participação de uma criança. Em relação a algum passeio de ônibus ou carro, observou-se a participação de seis crianças; nenhuma outra atividade foi citada como realizada pelas crianças nesse dia durante a semana. O tempo médio e a mediano gasto em cada atividade pode ser vista na (TAB. 4).

\section{TABELA 4}

Tempo médio e mediano (em minutos) gasto em cada atividade fisicamente passiva, durante a semana, fora da escola.

\begin{tabular}{l|c|c}
\hline \multicolumn{1}{c|}{ Atividade } & \multicolumn{1}{c}{$\begin{array}{c}\text { Semana } \\
\text { Média } \\
( \pm \text { desvio } \\
\text { padrão })\end{array}$} & $\begin{array}{c}\text { Mediana } \\
\text { (Mín-Máx })\end{array}$ \\
\hline Leitura & $14,8( \pm 20,1)$ & $0,0(0,0-60,0)$ \\
TV & $11,5( \pm 71,4)$ & $105,0(15,0-300,0)$ \\
Música & $35,8( \pm 40,5)$ & $30,0(0,0-120,0)$ \\
Conversa com amigos & $54,0( \pm 87,4)$ & $30,0(0,0-390,0)$ \\
Computador / Internet & $59,5( \pm 59,5)$ & $60,0(0,0-180,0)$ \\
Videogame & $14,0( \pm 31,9)$ & $0,0(0,0-120,0)$ \\
Brinquedos Industrializados & $25,5( \pm 29,8)$ & $10,0(0,0-90,0)$ \\
Deveres escolares & $45,5( \pm 41,4)$ & $40,0(0,0-120,0)$ \\
Modelar, montar, desenhar & $6,5( \pm 13,5)$ & $0,0(0,0-40,0)$ \\
Dormir & $12,0( \pm 32,9)$ & $0,0(0,0-120,0)$ \\
Escola de música, banda, coral & $2,0( \pm 8,9)$ & $0,0(0,0-40,0)$ \\
Curso de línguas & $7,0( \pm 22,5)$ & $0,0(0,0-90,0)$ \\
Passeio carro ou ônibus & $16,0( \pm 41,6)$ & $0,0(0,0-180,0)$ \\
Igreja & $9,0( \pm 27,7)$ & $0,0(0,0-90,0)$ \\
Outras atividades & $3,8( \pm 16,8)$ & $0,0(0,0-75,0)$ \\
\hline
\end{tabular}


João G. de Souza Junior, Guanis de B. Vilela Júnior e Mudanças Ocorridas na Cidade de Uberaba-MG... Rute E. Tolocka

De forma geral, quando analisadas a participação das crianças nas ativas fisicamente ativas realizadas durante a semana encontra-se que cada uma participa em média $121,5 \mathrm{~min}(2 \mathrm{~h} 1 \mathrm{~min})$, com mediana de $92,5 \mathrm{~min}(1 \mathrm{~h} 32 \mathrm{~min})$ (somado todas as atividades ativas), e nas atividades fisicamente passivas cada uma participa em média por um período de 416,8min (6h56min), com mediana de 420,0 min (7hs). A FIG. 1 apresenta o box-plot, ilustrando a distribuição de horas gastas durante a semana em atividades fisicamente ativas e passivas. Percebe-se claramente que as crianças estão gastando muito mais tempo em atividades fisicamente passivas.

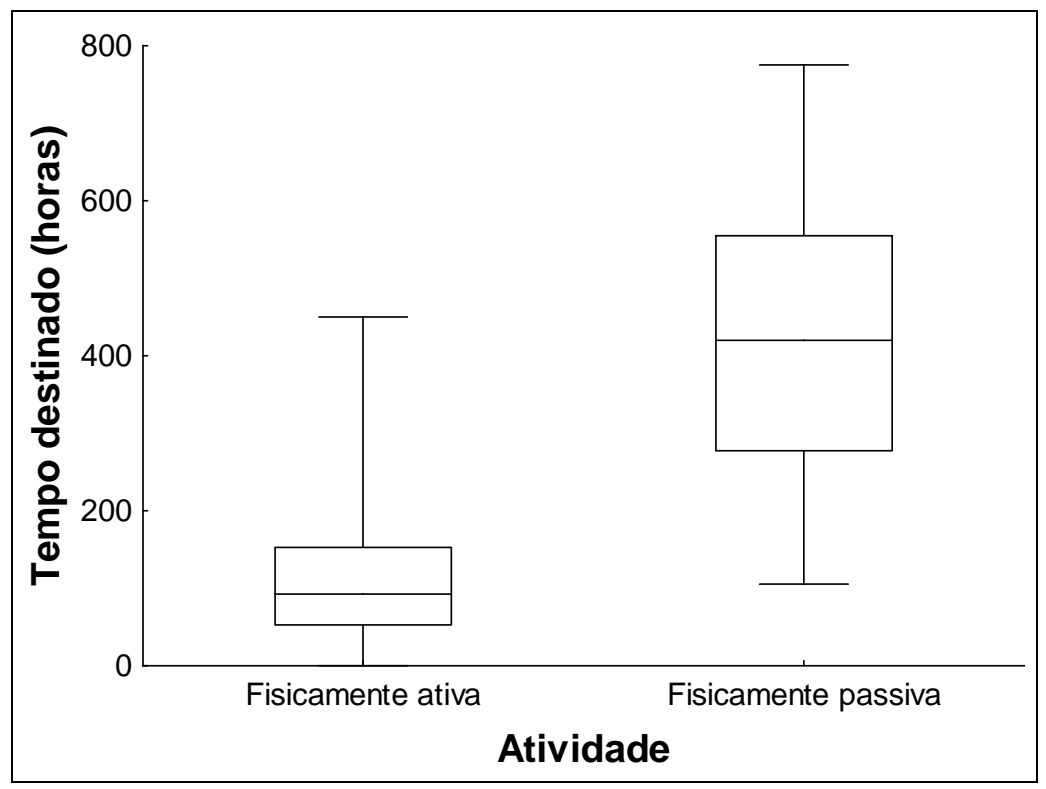

FIGURA 1 - Box Plot, com a distribuição das horas gastas em atividades fisicamente ativas e passivas durante a semana.

De acordo com Rodrigues et al (2007), o maior tempo gasto em atividades fisicamente passivas pode ser relacionado a alteração do estilo de vida das crianças, levando-as a utilizar menos as atividades motoras ativas. Os mesmos autores indicam que a tecnologia, na forma de computador, elevador, televisão e outros afins, atingem diretamente o cotidiano das crianças, estimulando-as a trocar o lazer na rua, pelos jogos eletrônicos. Carlos Neto (2005) enfatiza que as agendas repletas de atividades 
João G. de Souza Junior, Guanis de B. Vilela Júnior e Mudanças Ocorridas na Cidade de Uberaba-MG... Rute E. Tolocka

padronizadas contribuem para um modelo de vida elaborado e com tendência ao sedentarismo.

Foi observado que as crianças dormiram de sábado para domingo uma média de $565 \min (9 \mathrm{~h} 25 \mathrm{~min}$ ), sendo que a criança que dormiu por mais tempo, teve um sono com duração de $11 \mathrm{~h} 30$ min e a que menos dormiu teve um sono de $3 \mathrm{~h} 3 \mathrm{~min}$.

Em relação às atividades fisicamente ativas, relativas ao domingo, das sete crianças que participaram na tarefa de ajudar arrumar e a organizar a casa; apenas uma delas ajudou a cuidar de criança menor; nas atividades de andar sobre rodas (bicicleta, patins, skate, rolemã), foi encontrada a participação de quatro crianças.

Duas crianças participaram de algum jogo ou brincadeira que envolveu o chute, lançamento ou recepção de objetos com os pés; em relação a participação em algum jogo ou brincadeira ou atividade que envolve o lançamento ou recepção de objetos com as mãos encontrou-se a participação de duas crianças; nas atividades que envolvem jogos ou brincadeiras de correr, saltar, trepar ou outros deslocamentos, encontrou-se a participação de seis crianças.

Nenhuma criança participou da prática de algum esporte fora da aula de Educação Física, com orientação de um professor / orientador; de acordo com o levantamento sobre a participação das crianças em algum tipo de luta, não foi encontrado a participação de nenhuma, no tocante a dança como atividade foi encontrado a participação de três crianças; em relação a algum tipo de passeio a pé, encontrou-se a participação de quatro crianças; foi citada apenas a participação de duas crianças em outra atividade. O tempo médio e mediano gasto em cada atividade pode ser vista na ( TAB. 5). 
João G. de Souza Junior, Guanis de B. Vilela Júnior e Mudanças Ocorridas na Cidade de Uberaba-MG... Rute E. Tolocka

TABELA 5

Tempo médio e mediano (em minutos) gasto em cada atividade fisicamente ativa, no domingo.

\begin{tabular}{l|c|c}
\hline \multicolumn{1}{c|}{ Atividade } & \multicolumn{1}{c}{ Semana } \\
\cline { 2 - 3 } & $\begin{array}{c}\text { Média } \\
( \pm \text { desvio } \\
\text { padrão })\end{array}$ & $\begin{array}{c}\text { Mediana } \\
\text { (Mín-Máx })\end{array}$ \\
\hline Sobre rodas & $28,0( \pm 71,0)$ & $0,0(0,0-300,0)$ \\
Atividades com os pés & $7,5( \pm 27,3)$ & $0,0(0,0-120,0)$ \\
Atividades com as mãos & $6,0( \pm 18,5)$ & $0,0(0,0-60,0)$ \\
Atividades de deslocamentos & $45,0( \pm 84,6)$ & $0,0(0,0-240,0)$ \\
Escola de esportes & - & - \\
Luta & - & - \\
Dança & $8,3( \pm 21,5)$ & $0,0(0,0-75,0)$ \\
Passeio a pé & $3,5( \pm 10,9)$ & $0,0(0,0-40,0)$ \\
Outras atividades & $16,5( \pm 67,1)$ & $0,0(0,0-300,0)$ \\
\hline
\end{tabular}

No que se refere às atividades fisicamente passivas realizadas no domingo, encontrou-se que seis crianças leram (livro, revistas, jornais...); assistir TV apareceu citado como atividade de dezenove crianças; foi observada a participação de sete crianças, que ouviram música; de acordo com o levantamento sobre conversar com os amigos, encontrou-se 10 crianças; na atividade de jogar vídeo game foi encontrada a participação de quatro crianças; em relação ao uso do computador / Internet, encontrouse que nove crianças utilizou-se do mesmo; brincar com brinquedos industrializados foi uma atividade que sete crianças participaram nesse dia; foi citado que nove crianças estudaram ou fizeram deveres escolares nesse dia; apenas uma criança modelou, montou, desenhou, recortou ou fez colagem nesse dia; de acordo com o levantamento sobre quantas crianças dormiram, encontrou-se que apenas duas; não foi encontrada a participação de nenhuma criança em atividades relacionadas a escola de música, banda coral ou aula de canto, teatro, nesse dia; em relação a participação em algum curso de 
João G. de Souza Junior, Guanis de B. Vilela Júnior e Mudanças Ocorridas na Cidade de Uberaba-MG... Rute E. Tolocka

línguas, computação, ou outros, não foi encontrado a participação de nenhuma criança; a igreja foi freqüentada por oito crianças; foi citada a opção de passear de ônibus ou carro por 12 crianças; apenas duas crianças participaram de outras atividades; $\mathrm{O}$ tempo médio e mediano gasto nessas atividades podem ser vistos na (TAB. 6).

\section{TABELA 6}

Tempo médio e mediano (em minutos) gasto em cada atividade fisicamente passiva, no final de semana.

\begin{tabular}{l|c|c}
\hline \multirow{1}{*}{ Atividade } & \multicolumn{2}{|c}{ Final de Semana } \\
\cline { 2 - 3 } & $\begin{array}{c}\text { Média } \\
( \pm \text { desvio } \\
\text { padrão })\end{array}$ & $\begin{array}{c}\text { Mediana } \\
\text { (Mín-Máx })\end{array}$ \\
\hline Leitura & $7,3( \pm 15,7)$ & $0,0(0,0-60,0)$ \\
TV & $119,5( \pm 67,6)$ & $120,0(0,0-240,0)$ \\
Música & $21,8( \pm 43,5)$ & $0,0(0,0-180,0)$ \\
Conversa com amigos & $55,0( \pm 67,4)$ & $30,0(0,0-240,0)$ \\
Computador / Internet & $41,0( \pm 51,7)$ & $20,0(0,0-180,0)$ \\
Videogame & $20,0( \pm 37,8)$ & $0,0(0,0-120,0)$ \\
Brinquedos Industrializados & $30,0( \pm 49,6)$ & $0,0(0,0-120,0)$ \\
Deveres escolares & $35,3( \pm 46,2)$ & $0,0(0,0-120,0)$ \\
Modelar, montar, desenhar & - & - \\
Dormir & $8,3( \pm 28,2)$ & $0,0(0,0-120,0)$ \\
Escola de música, banda, coral & - & - \\
Curso de línguas & - & - \\
Passeio carro ou ônibus & $34,0( \pm 44,7)$ & $15,0(0,0-150,0)$ \\
Igreja & $27,8( \pm 35,9)$ & $0,0(0,0-90,0)$ \\
Outras atividades & $12,5( \pm 42,4)$ & $0,0(0,0-180,0)$ \\
\hline
\end{tabular}

De forma geral, quando analisada a participação das crianças nas ativas fisicamente ativas realizadas durante o final de semana encontra-se que cada uma participa em média 132,0min (2h12min), com mediana de 67,5min (1h $7 \mathrm{~min}$ ) (somando todas as atividades ativas), e nas atividades fisicamente passivas cada uma participa em média por um período de 412,3 min (6h, $42 \mathrm{~min}$ ) com mediana de 390,0 min (6h30min) (envolvendo todas as atividades), como se observa no Box-plot da (FIG. 2). 
João G. de Souza Junior, Guanis de B. Vilela Júnior e Mudanças Ocorridas na Cidade de Uberaba-MG... Rute E. Tolocka

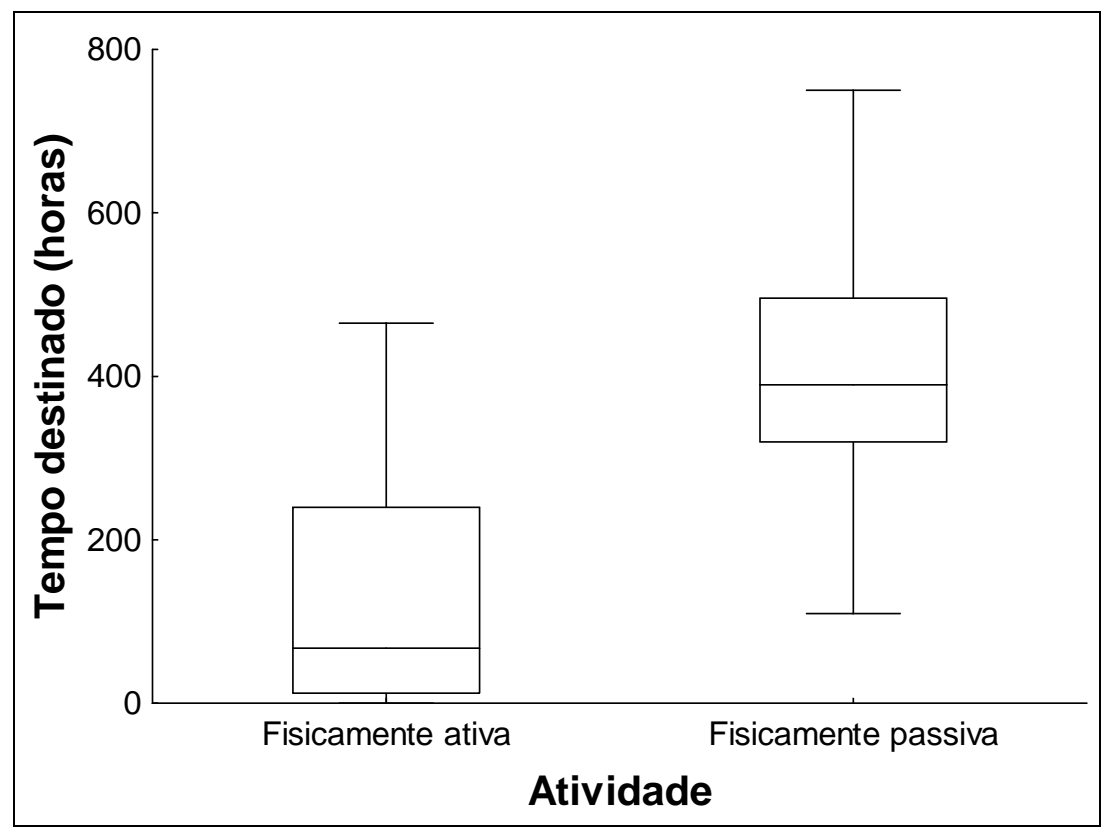

FIGURA 2 - Box Plot da distribuição das horas gastas em atividades fisicamente ativas e passivas, durante o final de semana.

Também no final de semana é notória a diferença entre a distribuição do tempo gasto pelas crianças, sendo que ocorre uma supremacia das atividades fisicamente passivas em relação as passivas, indo de encontro a Escobar e Valente(2007) que destacam que as atividades fisicamente ativas tem diminuído entre as crianças em detrimento do lazer inativo, praticado dentro de casa, com a utilização dos eletrônicos, tornando-as cada vez mais vulneráveis ao excesso de peso, e a outros prejuízos.

Diante dos dados expostos ficam claras as mudanças no ambiente da cidade de Uberaba-MG, pois a população aumentou o número de crimes, a frota de veículos, o sistema urbano, o número de alunos matriculados em tempo integral, porém o aumento em locais de lazer ou não ocorreram ou foram inexpressivos. Estes dados coincidem com os estudos de Brito (2006), Oliveira (2004), Silva e Nunes (2008), Prodócimo e Navarro (2008), Carlos Neto (2001) e Cavaliere (2007).

Essas mudanças provavelmente mudaram o estilo de vida das crianças, pois os resultados encontrados em relação às atividades desenvolvidas fora da escola 
João G. de Souza Junior, Guanis de B. Vilela Júnior e Mudanças Ocorridas na Cidade de Uberaba-MG... Rute E. Tolocka

evidenciam isto, uma vez constatado que as crianças estão brincando majoritariamente dentro de casa, provavelmente em função da violência que gera a insegurança. Essa constatação evidencia a necessidade de que as autoridades governamentais não somente construa novos espaços, pois isso somente não é suficiente, devem pensar em segurança, fazendo com que os pais tenham confiança em levar as crianças para brincarem nesses locais.

Outro dado importante é que mesmo no final de semana onde as crianças não freqüentam a escola, existe a preferência pelas atividades fisicamente passivas, isto é preocupante pois coloca a criança sob risco no seu desenvolvimento, no que tange ao crescimento físico, a criatividade e a interação social, pois os espaços da casa limitam o contato com outras crianças, o despertar da criatividade, além de sugerirem atividades com pouco gasto energético, o que pode levar a criança ao sedentarismo e obesidade.

A rua, campo ou terreno foram locais que quase não foram citados pelos pais, provavelmente pelo aumento da violência urbana e pelo excesso de veículos nas ruas, e em relação a campo ou terreno, percebe-se a diminuição do número dos mesmos em função da valorização mercadológica, sendo necessário que as cidades tenham um plano diretor que planejem o crescimento urbano, destinando áreas ao lazer, que contemplem as necessidades da criança.

Para finalizar, é importante ressaltar que essas alterações no estilo de vida das crianças não trouxeram somente aspectos negativos, pois a tecnologia constatada no cotidiano das crianças facilita a vida das mesmas, possibilita informações e pode contribuir com o desenvolvimento, desde que a criança não fique apenas envolvida no mundo virtual e que sejam utilizados também jogos fisicamente ativos. 
João G. de Souza Junior, Guanis de B. Vilela Júnior e Mudanças Ocorridas na Cidade de Uberaba-MG... Rute E. Tolocka

\section{Considerações Finais}

A cidade de Uberaba - MG apresenta alterações no seu ambiente, aumentando consideravelmente o número de habitantes, os crimes, a frota, o sistema urbano, o número de alunos matriculados em escola de tempo integral, sem o respectivo aumento em locais para a prática segura do lazer, o que tem levado crianças freqüentarem pouco os espaços públicos, sendo o quintal ou um cômodo da casa o lugar mais utilizado para brincar.

Como em outros estudos, estas alterações podem estar dificultando as possibilidades de realização de lazer com atividades fisicamente ativas, pois estas crianças estão gastando mais horas em atividades fisicamente passivas, o que pode acarretar prejuízos no seu desenvolvimento.

É importante ressaltar a necessidade de que as autoridades governamentais repensem políticas publicas sociais que possam atender a necessidade das crianças, fomentando projetos que envolvam atividades fisicamente ativas, investindo na segurança, melhorando o trânsito. Faz-se urgente um planejamento do crescimento urbano, destinando novos locais e programas que possam oferecer espaços seguros e possibilidades de brincar.

Além disso, profissionais de Educação Física, pais, pedagogos, diretores escolares, entre outros responsáveis pela educação das crianças, devem estimular e possibilitar as crianças uma maior participação em brincadeiras, jogos, esportes, com atividades fisicamente ativas, para que seja respeitado o direito ao lazer que a criança tem assegurado na legislação. 
João G. de Souza Junior, Guanis de B. Vilela Júnior e Mudanças Ocorridas na Cidade de Uberaba-MG... Rute E. Tolocka

\section{REFERÊNCIAS}

ABREU, C. N. et al. Dependência de Internet e de jogos eletrônicos: uma revisão. Rev. Bras. Psiquiatria, v. 30, n. 2, p. $156-167,2008$.

BRASIL - ECA. Estatuto da Criança e Adolescente. Brasília: Ministério da Justiça 1990.

BRITO, F. O deslocamento da população brasileira para as metrópoles. Estudos Avançados, São Paulo, v.20, n.57,p.221-236, 2006.

CAMPOS, T.; DEBORTOLI, J. A. O. Crianças nos sinais: Um olhar sobre o trabalho infantil e as possibilidades de vivências do lazer nas ruas de Belo Horizonte. Licere, v. 10, n.1, p.1-26, 2007.

CARLOS NETO. A criança e o jogo: perspectivas de investigação. In: B. Pereira. A escola e a criança em risco - intervir para prevenir. Porto: Asa, 2001. p.31-51.

\begin{tabular}{lcccc}
\multicolumn{2}{c}{. Jogo na criança e desenvolvimento psicomotor. Faculdade de Motricidade } \\
Humana. & Fev & 2005. & Disponível & em:
\end{tabular} http://www.fmh.utl.pt/Cmotricidade/dm/textoscn/jogonacriança.pdf > Acesso em: 20 jul. 2009.

CAVAliERE, A. M. Tempo da escola e qualidade na educação pública. Educ Soc. v.28, n.100, p.1015 -1035, 2007.

ESCOBAR, A. M. U. VALENTE, M. H.; Sobrepeso: uma nova realidade no estudo nutricional de pré-escolares de Natal, RN. Rev. Assoc. Méd. Bras. v.1. 53, n.5, p. 378379, 2007.

FARIA, M. C. M.; BROLO, A.L.R.; TOLOCKA, R. E. Análise das oportunidades de lazer no cotidiano infantil in Silva: Recreação, esporte e lazer - espaço, tempo e atitude. Recife: Instituto tempo Livre, p. 256 - 268, 2007.

KASSOUF, A. L. O que conhecemos sobre trabalho infantil? Nova economia. v.17, n.2, p.323-350, 2007.

NEVES, V. F.; CASSARO, E. R.; PIMENTEL, G. G. A. O lazer no cotidiano da cidade. Iniciação Científica-Cesumar, v.6, n.2, p.104 - 111, 2004.

OLIVEIRA, C. M. A. S. A formação da criança nas cidades. Pediatria, v.26, n.3, p.172 $-178,2004$.

PERROTTI, E. A criança e a produção cultural. In: ZILBERMAN, R (Org). A produção cultural para a criança. Porto Alegre: Mercado Aberto, p.7-27,1982.

PRODÒCIMO, E.; NAVARRO, M. S. Reflexões sobre o brincar, Rev. Iberoamericana de Educacion, v.4, n. 47, p.01-10, 2008. 
João G. de Souza Junior, Guanis de B. Vilela Júnior e Mudanças Ocorridas na Cidade de Uberaba-MG... Rute E. Tolocka

RODRIGUES, M. G.;PESSOA, V. M.; SILVA, S. M. Verificação no nível de independência de mobilidade de crianças, movimentum - Revista Digital de Educação Física - Ipatinga: Unileste-MG - v.2 - n.2, p.1 - 11, 2007. Disponível em:http://www.unilestemg.br/movimentum/index_arquivos/movimentum_V2_N2_rodri gues_fernanda_pessoa_vanete_2_2006.pdf > Acesso em: 20 jul. 2009.

SILVA, J. V. P. Crescimento, habilidades motoras básicas e cotidianas infantil de crianças de Campo Grande - MS. Dissertação (Mestrado em Educação Física) Universidade Metodista de Piracicaba, Piracicaba - SP, 2006.

SILVA, J. V. P.; TOLOCKA, R. E., Cotidiano Infantil: Mudanças nas últimas décadas. In: CONGRESSO CIENTÍFICO LATINO_AMERICANO DE EDUCAÇÃO FÍSICA, 4. Piracicaba: FACIS/UNIMEP, Anais... 2006, v.1, p. 1-3, 2006.

SILVA, J. V. P.; NUNES, P. R. M, A cidade, a criança e o limite geográfico para jogos/brincadeiras. Licere, v.11, n.3, p. 1- 13, 2008.

SILVA, J. V. P., TOLOCKA, R. E.; MARCELLINO, N. C. Lazer infantil: direitos legais, transformações sociais e implicações ao crescimento e habilidades motoras básicas. Licere. v.9. n.1 p.81-96, 2006.

TOLOCKA, R. E. et al. Perfil de crescimento e estado nutricional em crianças e creches e pré-escolares do município de Piracicaba. Rev. da Educação Física/UEM, v.19, n.3, p.343 - 351, 2008.

\section{Endereço dos Autores:}

Rute Estanislava Tolocka

R. Ezequiel Anastácio, 152 Jardim Planalto

Campinas - SP - CEP.: 13093-110

Endereço Eletrônico: nupemlab@gmail.com 